\title{
MULTISTAKEHOLDER PLATFORMS FOR LINKING SMALL FARMERS TO VALUE CHAINS: EVIDENCE FROM THE ANDES 1
}

\author{
Graham Thiele, André Devaux, Iván Reinoso, Hernán Pico, \\ Fabián Montesdeoca, Manuel Pumisacho, Jorge Andrade-Piedra, \\ Claudio Velasco, Paola Flores, Raúl Esprella, Alice Thomann, \\ Kurt Manrique, and Doug Horton
}

\section{Introduction}

Developing countries have seen the reconfiguration of value chains presenting new opportunities for adding value and raising rural incomes (Gibbon 2001). Supermarkets and large-scale food manufacturers have transformed agrifood markets in much of the developing world (Reardon and Berdegué 2002). There is an extensive literature about the effects of this new economy on the potential exclusion of small farmers, who produce small volumes on dispersed fields and struggle to meet demands for quantity, quality, and timeliness of delivery. The difficulty is compounded by a lack of trust among farmers and other value-chain actors, which generates high transaction costs and short-circuits innovation. A recent review by Reardon et al. (2009) confirmed a mixed picture with some exclusion of small farmers in contexts where small and large farmers coexist, but also evidence of positive effects on income and assets of small farmers where inclusion occurs. Reardon et al. (2009) pointed out the critical nature of nonland assets such as inputs, credit, association, and extension, and the role of government to help small farmers "make the grade." Many ongoing initiatives seek to improve value chains and favor poorer farmers (Harper 2010).

1 The authors thank Valerie Gwinner, Laurens Klerkx, Sietze Vellema, and three anonymous reviewers for valuable comments and suggestions on earlier drafts of this paper, and Roger Cortbaoui for encouraging us to develop platform concepts. We appreciate the support of farmers and staff, Ecuador's National Institute for Agricultural and Livestock Research (INIAP), Bolivia's Promotion and Research for Andean Products (PROINPA) Foundation, and numerous other partners and projects acknowledged in the original article, who contributed to developing and testing ideas about platforms. We are especially grateful to SDC and the New Zealand Aid Programme, which provided funding and vision for the work of the Papa Andina program, which inspired this chapter. 
This chapter explores the role of multistakeholder platforms in promoting inclusion of small farmers. It considers three different platforms with potato value chains in the Andes (Bolivia, Ecuador, and Peru). It presents a framework for characterizing and understanding platforms, with an action arena comprised of innovation and market governance. It then assesses evidence of the platforms' effectiveness and flags areas for future work.

\section{Literature Review and Theoretical Framework}

The term platform is in vogue. Sometimes it refers to a methodology, such as Farmer Field Schools (FFS), or to any group that comes together for joint action. Building on Röling, Leeuwis, and Pyburn (2002) and Thiele et al. (2005), we define a multistakeholder platform as a space of interaction among different stakeholders who share a common resource and interact to improve mutual understanding, create trust, define roles, and engage in joint action. Henceforth we refer to this as a "platform." It is related to the concept of learning alliances which promotes multistakeholder learning processes for stimulating innovation and business development, but differs in that it has a clearly bounded membership linked to a shared resource (Lundy, Gottret, and Ashby 2005).

Platforms involve stakeholders of diverse types, with different interests, ways of making a living, and assets. A producer cooperative is not a platform, because it includes only one type of actor. A platform has value for stakeholders, because they are, or may become, interdependent. Interdependence can create tension, conflict, maneuvering to seek advantage, and even group displacement. But it also opens opportunities for mutual understanding, building confidence, social learning, and joint action (Röling, Leeuwis, and Pyburn 2002). The platform makes possible actions that none of the members could have achieved on their own. Because of its complex membership and potential for conflict, a platform is likely to require facilitation and may have a lengthy initial phase of mutual learning and role definition, before it can get down to business (Thiele et al. 2005).

Stakeholders can have different roles in a platform. We distinguish platform members who are the core actors who make up the platform; partners who interact with the platform, contribute to defining its objectives, and share information and other resources; and clients and providers who may receive goods or services from the platform or provide them on a commercial basis. In practice, these categories may be somewhat blurred and some members may be more passive than partners. 
Multistakeholder platforms were first proposed in the context of naturalresource management, where stakeholders share a common-pool resource, such as access to water in a river basin, and the platform contributes to the collective management of the resource (Röling, Leeuwis, and Pyburn 2002). The use of platforms in the context of value chains is less frequent. A recent overview of collective action for small-farmer market access considered small-farmer organizations, but did not mention platforms (Markelova et al. 2009). One exception is Vellema et al. (2009), who analyze an oilseedsubsectoral platform in Uganda.

In a value chain, a platform can perform three different but interlinked functions. First, it can create a space for learning and joint innovation, as innovation intermediary or broker. Second, it can perform a governance function within the value chain to improve coordination of business activities by actors and reduce transaction costs. Finally, a platform can perform advocacy functions to secure policy change or influence. We concentrate on the first two functions.

\section{Learning and Innovation}

Increasing attention is being given to intermediaries or brokers to promote innovation (Howells 2006). Klerkx, Hall, and Leeuwis (2009) recognize that new types of systemic intermediary are needed to broker innovation in a complex innovation system. Klerkx and Leeuwis (2009) describe the key innovation brokerage functions as: (1) demand articulation, which articulates innovation needs and corresponding demands; (2) network formation, which facilitates linkages between relevant actors (scanning, scoping, filtering, and matchmaking of possible cooperation partners); and (3) innovationprocess management.

Platforms have been also used as a type of innovation intermediary in the experiences described here in the Andes. In this sense, they complement, and (in two of the cases, Bolivia and Peru) build on, the Participatory Market Chain Approach (PMCA): a three-stage facilitated process that promotes innovation by strengthening trust and constructive interactions among chain actors (Bernet, Thiele, and Zschocke 2006). In a similar vein, Critchley, Verburg, and van Veldhuizen (2006) have emphasized the role of platforms as a space or theater for innovation involving different stakeholders.

\section{Value-Chain Governance}

Value-chain governance may be provided by: (1) market mechanisms, (2) hierarchical nonmarket mechanisms, and (3) nonmarket-based voluntary coordination between actors of a collective action type (Markelova et 
al. 2009). Dorward et al. (2009), writing from a new institutional economics perspective, note that coordination provided through different nonmarket mechanisms can help market actors reduce transaction costs and escape the low-level equilibrium trap associated with underdeveloped economies as a weak institutional environment and high transaction risks limit investment opportunities.

Developed countries have seen the emergence of supply-chain management, defined as the "integration of key business processes from end-user through original suppliers that provide products, services and information that add value for customers and other stakeholders" (Lambert 2008). Given the increasingly "disintegrated" nature of supply chains made up of different enterprises in automotive, textile, and electronic industries, Bitran, Gurumurthio, and Lin Sam (2006) postulate the need for a neutral third player or maestro to coordinate the network of suppliers.

The need for increased integration in developing countries and the disintegration of more hierarchically organized supply chains in developed countries has created a curious convergence with the need for new types of institutions to facilitate value-chain governance. As we shall see below, platforms have provided one such institutional mechanism for this market-governance function.

The Institutional Analysis and Development (IAD) framework was developed to explain the functioning of common-pool resource systems and has been applied in many empirical contexts (Ostrom 2005, 2010). The focus is on understanding the formal and informal rules that affect behavior in an action arena, where actors interact, make decisions, take actions, and experience the consequences of these actions. Behavior in the action arena is conditioned by: (1) biophysical conditions, (2) the attributes of community, and (3) the set of rules in use. Behavior in the action arena determines outcomes, and these outcomes and the valuation that actors make of them reshape the external variables and the action arena.

The present chapter further develops the IAD framework to understand the role of platforms in a value chain (Figure 8.1). It specifies as external variables the biophysical and material characteristics of the value chain, characteristics of the chain actors, and institutional arrangements which can be described as a set of rules. The rules are of quite diverse types, some have to do with who can be a member of the platform and what roles they may perform, and others to with the types of benefit they receive through membership. Some of the rules are implicit, while others, as we shall see, are explicit and written. These external variables jointly determine and shape possibilities in the action arena made up of innovation and governance sub-arenas. These 
FIGURE 8.1 Framework for analyzing collective action in value-chain innovation and governance

Value chain

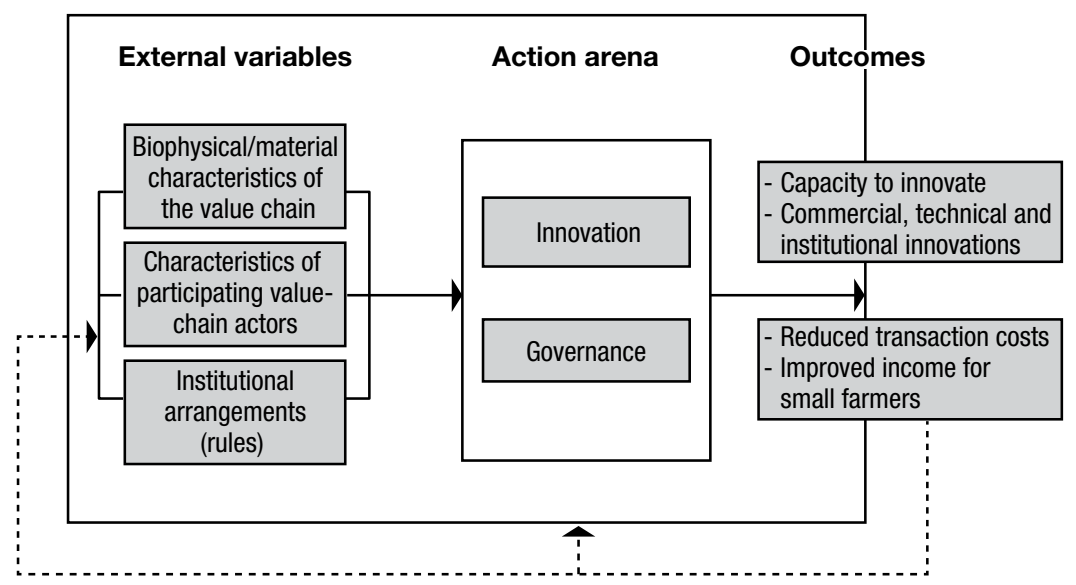

Source: Adapted from Devaux et al. (2009).

sub-arenas interact as innovation can generate new governance opportunities, and improved governance interacts with innovation processes. Finally, actions in each sub-arena lead to a range of linked outcomes and benefits for actors. Next, we apply the IAD framework to analyze the three platforms and their contribution to stimulating innovation and improving governance.

\section{Platforms Compared}

The three platforms we compare are: Andino Boliviana (ANDIBOL) in Bolivia; Cadenas Agrícolas Productivas de Calidad (CAPAC) in Peru; and the Chimborazo platform in Ecuador. ${ }^{2}$ We begin by examining the three sets of external variables that condition the action arena of the platforms. We describe the platforms in the present tense, and the description relates to their status when this study was initiated. The Chimborazo platform was substantially restructured in 2006 .

2 These platforms were brought together by the Papa Andina Partnership Program of the International Potato Center (CIP). Papa Andina encouraged the development of the platform concepts and cross-learning between partners (Thiele 2007; Devaux et al. 2009). 


\section{Biophysical and Material Characteristics of the Market Chain}

Potato production in the Andes involves a mix of small, medium, and (in Peru and Ecuador) large farmers. Small farmers typically occupy land at higher altitudes, with poorer access, less input use, and often grow a relatively larger area under native varieties (landraces). Medium and larger farmers occupy higher-quality valley-bottom land, with better access and more input use, and typically have a much larger share of marketed production.

Most potatoes in value chains in Bolivia, Peru, and Ecuador still go through traditional market channels, with a large number of rural assemblers, supplying wholesale urban markets and a network of urban retail markets with graded potatoes of a considerable range of varieties sold loose to the consumer. In general, this market appears to be fairly efficient, with no clear evidence of excessive levels of intermediation (Scott 1985). The market is dominated by spot prices with high price volatility. Transaction characteristics with small volumes managed by each market intermediary make it difficult to plan for investments in improving product quality, and hinder innovation.

The three platforms described link farmers with high-value chains rather than with traditional market chains. These offer more scope for value-added, with potentially higher and more stable farmgate prices (in some cases with forward contracts), but may require considerable innovation for the entry of small farmers if they are to meet stricter quality and quantity criteria. In Peru and Bolivia, the focus is on native potatoes, one of the assets of poorer farmers, grown primarily for home consumption or local markets (Meinzen-Dick, Devaux, and Antezana 2009). Native potatoes were selected as having the greatest probability of generating benefits to poorer farmers as value-chain upgrading takes place. In Peru, the target market for native potatoes centers on high-income consumers in Lima, a large city with a growing middle class and a rapidly expanding agroindustrial sector. The challenge is to create a niche market for native potatoes as part of a more general interest in Andean cuisine. In Bolivia, while the market also centers on native potatoes and derivative products, the middle class is much smaller and there are no large agroprocessors, so nontraditional retail outlets are the primary market. In Ecuador, native potatoes are much less widely grown and the market opportunity is a large agroindustrial chip producer, and fast-food outlets and restaurants which need potatoes for French fries. Medium and large farmers predominantly access this value chain, so the challenge is not to stimulate the creation of a new market, but to create a space for small farmers within an existing one. 


\section{Characteristics of Participants}

In each case, an agricultural research organization assumed the role of platform facilitator: the PROINPA (Promoción e Investigación de Productos Andinos) Foundation in Bolivia; Instituto Nacional Autónomo de Investigaciones Agropecuarias (INIAP) in Ecuador; and the International Potato Center (CIP), through the Innovación y Competitividad de la Papa (INCOPA) project, in Peru. All these partners had experience with participatory approaches for on-farm research, but had not engaged multiple stakeholders to work with markets. The research organization learned how to assume a new role in facilitation of the process of platform creation and to "step back" and play a subsidiary role in research to address specific market constraints.

The CAPAC (Peru) and ANDIBOL (Bolivia) platforms were established by INCOPA and PROINPA, respectively, resulting from applications of the PMCA with native potatoes, as more permanent forums to support the innovation process (Devaux et al. 2009). In the PMCA, the participation of private market-chain actors as members and partners to develop new business opportunities underpins the innovation process (Bernet, Thiele, and Zschocke 2006). ANDIBOL includes food-processing companies, such as Ricafrut, Ascex, and Bolivia Natural; farmer organizations, such as Asociación de Productores Ecológicos de la Provincial Aroma (APEPA); nongovernmental organizations (NGOs), such as Kurmi Foundation; and others (Table 8.1). CAPAC interacts with some private-sector actors as members (formal membership), including Mi Chacra, a supplier of marketing information; the Gastrotur cooking school; potato processors, including Frito-Lay, a multinational chip producer; and the Wong supermarket group. Researchers and other agricultural service providers, including the NGOs Asociación Fomento de la Vida (FOVIDA) and Asociación para el Desarrollo Sostenible (ADERS), promote and support these market-driven platforms.

In Ecuador, the INIAP team, which facilitated the creation of the Chimborazo platform, was critical of the PMCA; they felt it paid insufficient attention to farmer empowerment and perceived a risk of capture of the benefits of innovation by the private sector. However, they recognized that broader impact for agricultural research means engaging a broad range of stakeholders with a clearer market orientation. The Chimborazo platform brings together 28 farmer organizations and a group of service providers comprised of three NGOs, two universities, and INIAP itself. Frito-Lay and restaurants serving French fries in Riobamba and Ambato are involved, but as clients rather than 
full partners. Here the meshing of farmers and service providers in the platform is the driver of the innovation process.

\section{Institutional Arrangements (Rules)}

Engaging such diverse sets of stakeholders for collective action in value chains requires a broad set of rules to guide and shape their interaction. Some rules are explicitly formulated-all platforms have written statutes that define their mandate or mission, and describe leadership positions (Table 8.1). Other rules are implicit or informal.

In CAPAC and ANDIBOL, rules about platform membership embodied in formal statutes give private market-chain actors a privileged position, as their decisions about new market opportunities underpin innovation options. Researchers and other service providers play a supporting role in sustaining innovation.

In the Chimborazo platform, INIAP seeks to build on the existing mandates and interests of a group of research and development (R\&D) actors or service providers in the potato sector, recognizing that each has a particular competence, but guided by a new set of institutional rules called the "New Institutionality," whereby each can best capture their comparative advantage (Crespo et al. 2005). Farmers organize the production process and demand an array of services provided by R\&D organizations; NGOs provide technical assistance; and research organizations develop new technology to facilitate small-farmer entry into markets. Value-chain actors such as restaurants and supermarkets are treated as clients. These rules are most clearly articulated around multistakeholder platforms conceived as local alliances between farmers and R\&D organizations. INIAP helped set up four platforms (among them the Chimborazo platform) differentiated by market catchment area. The rules for identifying and engaging actors are specified through a methodology that stipulates a series of steps in setting up the platform around a market opportunity (Reinoso et al. 2007). The steps include stakeholder mapping to identify and engage relevant platform members, and designation of one of the service providers to host the platform and assume more specific facilitation responsibilities.

Each of the platforms has different rules regarding the outcomes which they can affect. CAPAC and ANDIBOL have mandates to promote and develop value chains for potato and other Andean tubers and Andean products (Table 8.1). As discussed above, in these platforms it is the participation of private market-chain actors that drives innovation. In order to ensure that benefits flow to small farmers, both platforms have complementary 


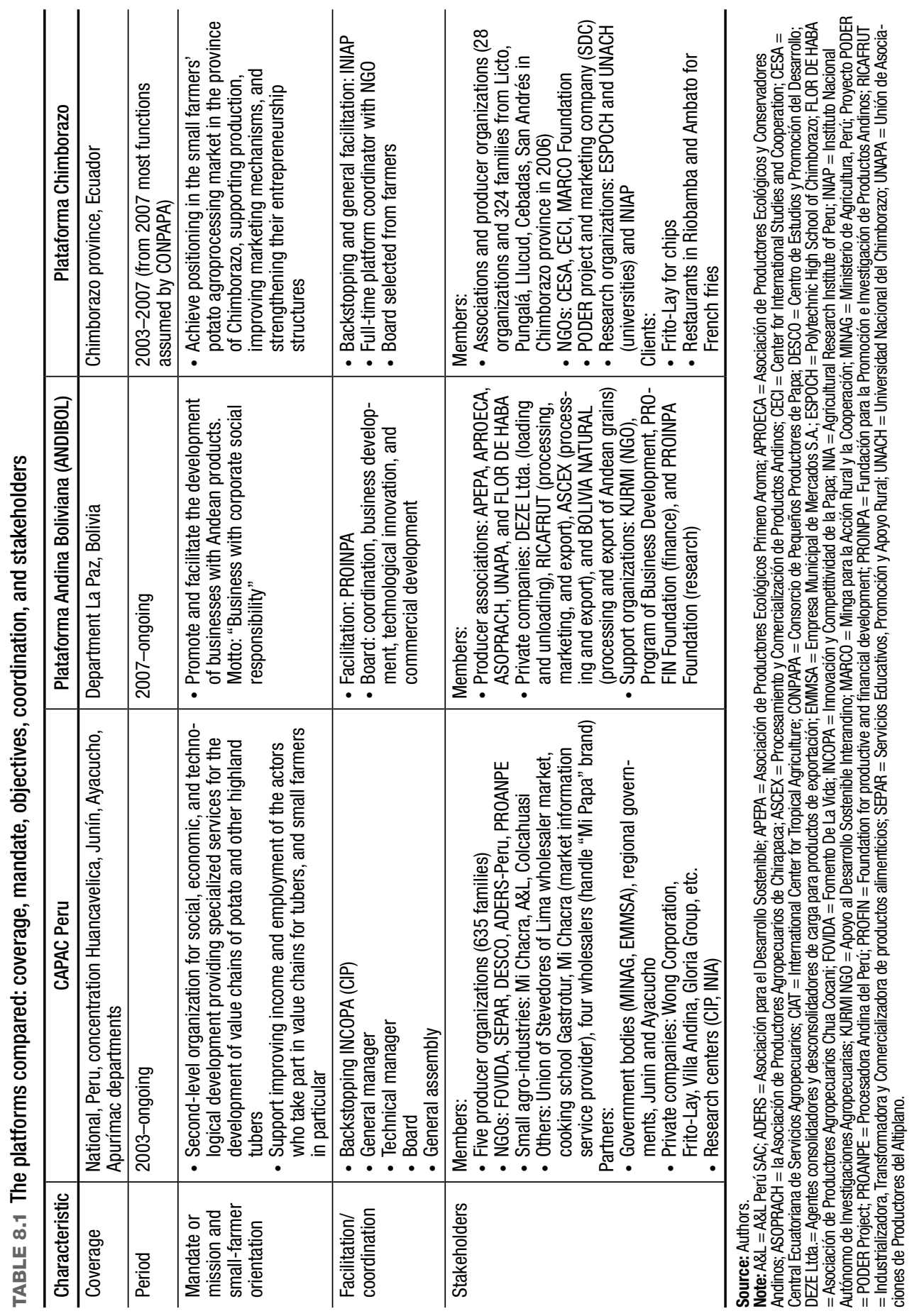


rules, embodied in the formal objectives of the platforms, concerned with the inclusion of small producers and corporate social responsibility (CSR) (Thomann et al. 2011).

The Chimborazo platform focuses explicitly on strengthening small-scale potato producers and positioning them in the market for processed potato. Here it is the meshing of small farmers and service providers that drives the innovation process. Many farmers attend platform meetings and are active participants. The Chimborazo platform treats private-sector actors as clients rather than as members or partners, and they do not attend ordinary platform meetings. Initially, the primary client was seen as Frito-Lay, but in practice it was difficult to meet the more demanding quality (levels of reducing sugars), quantity, and continuity requirements imposed by this large agroindustrial client. As a result, the most important group of clients are restaurants serving French fries in the cities of Ambato and Riobamba.

We turn now to discuss the action arenas of the platforms.

\section{Action Arena}

CAPAC as a platform has only one annual general assembly; other stakeholder interaction is project- and activity-specific. In practice, involvement of some private-sector partners is more active than that of some formal members. CAPAC was created as a result of the application of PMCA with the intention to support and consolidate the innovations that had been generated earlier and to promote additional innovation. It has some action in the innovation arena, for example in technical normative commissions that can change product-quality parameters and in promoting the use of CSR among private-sector actors. However, it has become increasingly active in the governance arena, providing business services on a not-for-profit basis for linking farmers to the supply chain of processors like Frito-Lay (for example, contract management, quality control). CAPAC also plays a role in advocacy and promotional activities (for example, as National Potato Day co-organizer).

ANDIBOL has regular monthly meetings with a principal focus on stimulating new product development by its members, and supporting innovation to address market constraints. Although set up with facilitation from PROINPA, the interest in developing new businesses has meant that private-sector actors have taken a more proactive role and are seeking additional funding. At the time of writing in 2009, ANDIBOL members are reframing and redefining the set of internal rules and statutes governing the operation of the platform and members' behavior to promote trust and 
improve decisionmaking. Specifically, they are working on the definition of rules related to the entry of new members and those associated with the use of the "Chef Andino" trademark and "ANDIBOL" certification hallmark, both created by the platform. The first will be used as a commercial image to introduce new products to urban markets, and the second as a certification label to show that products have been developed with CSR (and generating benefits flowing back to small producers).

The Chimborazo platform has monthly meetings which focus on planning production, meeting quotas for delivery to clients, and overcoming technical constraints to improve the quantity and quality of potatoes produced. These platform meetings build on and complement planning by the NGOs and the farmer organizations they work with to meet their shares of the quota. One of the first activities of the Chimborazo platform was to coordinate farmer training through the implementation of FFS. INIAP and other NGO partners had organized FFS previously (Pumisacho and Reinoso 2003), but this was the first time that they were articulated around a specific market opportunity. The FFS covered traditional topics in integrated pest and crop management linked to the introduction of a new processing variety, Fripapa, ${ }^{3}$ and also included new sessions on marketing, leadership, production costs, and pesticide management. INIAP trained NGO staff and farmer promoters as FFS facilitators, and provided backstopping to FFS implementation. The farmer training linked to the platform was substantial, and played a key role in facilitating technological innovation linked to the new variety to enable small farmers to meet quality and quantity parameters set by the market (Cavatassi et al. 2009).

The Chimborazo platform also planned interactions with clients and partners to capture demands and build networks to link producers with suppliers. In 2004, for example, a business roundtable was held with potential clients, primarily restaurants, for the Fripapa variety (suitable for frying) and other improved varieties. This had stands with information about research and training activities of the platform, production plans to assure regular supply, and bags of Fripapa with the CONPAPA label. The Cooking School from the local university Escuela Superior Politécnica del Chimborazo (ESPOCH) prepared French fries and other processed potato products, and restaurants were asked to estimate purchasing needs by variety (Reinoso et al. 2007).

3 Processed variety released by INIAP from clones provided by CIP. 


\section{Innovation Outcomes}

CAPAC played a critical role in the creation of trademarks for native potatoes, a type of commercial innovation. First, CAPAC's collective trademark "Mi Papa" recognizes quality across a diverse range of potato-based products. Second, the "Andean Potatoes Label" is a certification trademark for native-potato trade with CSR. CAPAC participated in the public-private workgroup to define quality parameters tor selling under the label and was chosen by the group to be the legal owner of the brand (Thomann et al. 2011). CAPAC also provides expertise to private partners for the creation of new products. It helped establish "Ayllin Papa," a product owned by a provider of the Wong supermarket, with clean, graded, bagged, and labeled native potatoes, which targets the gourmet high-value market.

With regard to technological innovation, production of native potatoes in Peru is highly seasonal, and sprouting and dehydration lead to progressive loss of market quality after the peak period of harvest. CAPAC linked with researchers at CIP to extend the period of supply through modifications to storage methods and the use of sprout inhibitors in stored potatoes (Manrique and Egusquiza 2009).

ANDIBOL has also acted as broker for technological innovation. "Chuñosa" is a packaged and graded product made from chuño, an artisanally freeze-dried potato that can be stored for long periods of time and is a key ingredient in some local dishes. Chuño is normally produced using very basic technology, under unhygienic conditions, and sold ungraded with impurities. The Ricafrut processing company, which owns the Chuñosa label, wanted to improve the product. They requested help to improve the quality and grading of the chuño raw material. The platform brokered this demand to improve cleanliness, grading, and presentation with PROINPA and Kurmi Foundation, which subsequently carried out participatory research to develop a potato peeler and grader. The manager of Ricafrut visited the production area to see how the machines performed and verify if the chuño obtained met market quality standards.

The Chimborazo platform only played a limited role in commercial innovation. This was related to the material characteristics of the market chain. The platform did not develop any new products, but instead sought to exploit existing market opportunities for French fries with restaurants in Ambato and Riobamba. It played a central role in articulating the demand for a potato suitable for frying from the platform's clients, refining the technology for the supply of quality potatoes of the Fripapa processing variety 
from small farmers through the FFS, and establishing local farmer capacity for multiplying high-quality seed. This was a complex technological innovation. Because processing characteristics are variety-specific, the exploitation of a new market for potatoes for French fries, which involved a specific technological innovation (the new variety), triggered a series of other innovations. For example, restaurants prefer larger tubers for French fries. But Fripapa, initially selected by breeders for chipping, produces predominantly medium-sized tubers. This demand for larger tubers was brokered through the platform and led to the implementation by INIAP of research on planting densities and fertilization to increase the percentage of larger tubers and acceptability by the restaurants.

All three platforms stimulated market-linked innovation functioning to differing degrees as innovation facilitators or brokers performing brokering functions described by Klerkx et al. (2009). The type of innovation which occurred was shaped by the material characteristics of the value chains and the characteristics of the participating actors. For CAPAC and ANDIBOL, where a new market opportunity was created, commercial innovation was especially important and specific innovations, such as trademarks, were developed to ensure that benefits from value-chain upgrading flow back to small farmers. For the Chimborazo platform, where an existing market opportunity was exploited and innovation was driven by linking small farmers and service providers, technological innovation around the Fripapa processing variety predominated. The innovation outcomes in all cases were complex and would have been hard to achieve by a single R\&D actor on its own. They involved an interaction between commercial and technological innovation, involving both private value-chain actors and service providers in the platforms in Peru and Bolivia, and a complex technological innovation combining varietal change, improvements in quality, and adjustments in cultural practices coordinated between service providers and farmer organizations in Ecuador.

\section{Market Governance Outcomes}

In Peru, CAPAC has been instrumental in providing transparent information on price and volumes. It has assumed an important role in market governance by linking farmers' native potato production to Frito-Lay and Ayllin Papa through intermediary NGOs. Indeed, in the areas where no local partner (NGO) is available, CAPAC carries out more specific and local marketgovernance tasks (contract management, quality control, and delivery at the plant) that cannot yet be handled by farmer organizations, and provides them with orientation and capacity building for planning, production, and 
postharvest management. In these areas, planning meetings among CAPAC and farmer representatives are held at the beginning of every planting season to establish quotas by area and planting times to organize production supply. This direct role as marketing agent may conflict with that of a national stakeholder platform, providing transparent information on native-potato supply and a higher-level integration function with the intermediary NGOs.

In Bolivia, ANDIBOL played an important facilitating and coordinating role, linking farmer organizations with exporting companies, and contributing to the supply of quality chuño for the export market. Without ANDIBOL it would have been impossible for chuño to enter export markets (Enrique Rivas, pers. comm.).

The Chimborazo platform played the most extensive role in market governance. The platform developed and monitored production plans with farmer quotas by market catchment areas to smooth the supply of potatoes to clients. This supply-chain management function was time-consuming and involved most of the time of the coordinator of the Chimborazo platform working with the intermediary NGOs. In addition, the platform empowered farmer organizations and associations to assume a greater leadership role. This began with FFS, which helped build social capital by creating trained and organized groups and included specific training in leadership with a particular emphasis on women. This process of empowerment led to the creation of Consorcio de Pequeños Productores de Papa (CONPAPA, Consortium of Small Potato Producers), which from late 2006 took over the technical assistance, production planning, bulking up, and marketing functions that the Chimborazo platform had previously performed.

\section{Impacts}

The scale, sequence, and timing of the impacts of the platforms - understood as livelihood improvements for small farmers-differed. Platforms in Peru and Bolivia primarily involve the creation of new market opportunities for native potatoes with innovation brokering along a value chain, and benefits flowing back from the value chain to the small farmers. The immediate benefits of innovation brokers are often intangible and the time frame for change to work its way through the innovation system may be quite long (Klerkx et al. 2009). But because private market-chain actors are driving the innovation process, this change may be more pervasive and sustainable. In contrast, in Ecuador the platform was oriented toward existing market opportunities structured around geographically delimited supply areas composed of small farmers, and has primarily addressed market-governance problems in assuring 
volumes, meeting quality and timeliness constraints, as well as empowering farmers. This generates a more immediate and higher impact but, because engagement of the private sector is weaker, the eventual scale of the impact could be less than in the first case.

In 2009 the companies linked to ANDIBOL sold over 9,000 halfkilogram bags of Chuñosa and nearly 3,300 boxes of Chef Andino. Exports have begun to Spain, so far benefiting 70 families directly, who receive US $\$ 1.10 / \mathrm{kg}$. These products are still in a pilot stage of development and the final market size and potential for increased farmer income is not yet clear.

In Peru, there has been a rapid growth of native potato marketed through CAPAC and its members to Frito-Lay, the fresh market, and as seeds, doubling from 2008 to 2009 and reaching over 400 tons. ${ }^{4}$ Farmers selling through these channels received around double the price in traditional markets, with a profit margin over 20 percent, and reported significantly higher yields.

The clearest and largest evidence of impact comes, as expected, from the platforms in Ecuador (Cavatassi et al., 2009). By 2007, some 1,483 tons of potato from 260 ha were marketed through the platforms by smallholder farmers (average landholding $2.6 \mathrm{ha}$ ). Platform farmers obtained an average yield 33 percent higher than nonparticipants. Their input costs were also higher, but despite this their profit (gross margins) was approximately four times greater thanks to the higher yield and a 30 percent higher selling price. Secondary indicators suggest that the linking to the platforms did not lead to negative consequences for farmers from the intensification of agricultural production (careful attention was given to risks and precautions regarding pesticide use and to integrated pest management in FFS training).

\section{Outstanding Questions and Issues}

\section{Limited Underlying Conceptual Base and Methodology}

Despite developing a general definition of platforms and exchanges of ideas among partners, there has been little explicit theory behind the creation of the platforms. One attempt to provide a more general explicit theory was published but not widely applied among Papa Andina and its partners (Thiele et al. 2005). Theory behind platforms has been mostly implicit and the platform facilitators involved followed their noses in pragmatically developing the

4 Ton means metric ton throughout. 
platforms. Only one platform (Ecuador) had a specific procedure for implementation (Reinoso et al. 2007). This lack of conceptual base, combined with the complexity of the challenges faced in increasing competitiveness of inclusive value chains, may explain why the platforms have sometimes taken on potentially conflicting functions (for example, legal owner of collective or certification brands, and market-chain facilitator for a specific geographic area and/or specific private-sector partners).

\section{Funding Mechanisms and Sustainability}

All three platforms have had subsidies provided through project funding. This was probably a reasonable investment which generated acceptable returns to the use of public funding, as shown by the impact study of the Plataforma program in Ecuador (Cavatassi et al. 2009). But in the longer run, and for scaling up, other funding and management mechanisms should be explored. One such mechanism could follow the lines of US levy boards, which are funded through levies on both potato producers and purchasers (www.idahopotato.com/), or models mixing levies and income from services (www.swisspatat.ch). These are backed by government legislation and function in a very different institutional environment. Securing funding for the function of innovation broker where the services provided are less tangible is a challenge even in the Netherlands (Klerkx, Hall, and Leeuwis 2009).

\section{Conclusion}

This chapter uses the IAD framework to understand the dynamics of three platforms linked to value chains. While all three platforms share some features, the material characteristics of the market chains they support, the characteristics of participating actors, their different underlying development paradigms, and institutional arrangements, mean that two different types of platform can be distinguished. In the first, the platform brings traders, processors, supermarkets, researchers, chefs, and others together with farmers and their associations to foster the creation of new market opportunities and commercial, institutional, and technological innovation with greater possibility of added-value for small farmers. In the second, the platform is structured around a geographically delimited supply area, meshing small farmers and service providers, and primarily addressing market-governance problems in assuring volumes, meeting quality and timeliness constraints, as well as empowering farmers, with a focus on technological innovation. Both types show indications of success, although the timescales to generate impacts 
are rather different, and more time is needed to judge which would be most appropriate under what circumstances.

The platform in Peru began as the first type, but subsequently shifted toward the second, perhaps because as commercial innovations were consolidated governance became a more pressing concern. This raises a more general concern that, because of the more tangible nature of the services delivered, governance functions in platforms may tend to displace those of innovation brokers. Once this risk is appreciated, careful attention to the institutional rules which guide the functioning of the platforms could help maintain the broker function.

The evidence from these cases suggests that platforms can bring together diverse stakeholders and contribute to new products, processes, norms, and behaviors oriented toward value chains, which could not have been achieved otherwise. In addition, platforms can achieve significant outcomes, increase farmer income, and help lift small farmers out of the low-level equilibrium trap (Cavatassi et al. 2009). More systematic evaluation is still needed to assess the impacts of platforms and their cost-effectiveness relative to other types of innovation broker and mechanisms for improving market governance. Up to now, platforms have lacked a coherent theoretical framework, making their assessment more difficult. We hope that this chapter will encourage more rigorous comparative analysis and wider use of multistakeholder platforms in value-chain innovation and governance.

\section{References}

Bernet T., G. Thiele, and T. Zschocke, eds. 2006. Participatory Market Chain Approach (PMCA)— User Guide. Lima, Peru: International Potato Center (CIP).

Bitran, G., S. Gurumurthio, and S. Lin Sam. 2006. Emerging Trends in Supply Chain Governance. Working Report. Cambridge, MA: MIT Sloan School of Management.

Cavatassi, R., M. González-Flores, P. Winters, J. Andrade-Piedra, P. Espinosa, and G. Thiele. 2009. Linking Smallholders to the New Agricultural Economy: An Evaluation of the Plataformas Program in Ecuador. Agricultural Development Economics Division Working Paper No. 09-03. Rome: Food and Agriculture Organization of the United Nations.

Crespo, P., D. Guerrero, P. Iturralde, X. Mera, C. Monteros, F. Montesdeoca, H. Pico, et al. 2005. Hacia Una Nueva Institucionalidad de la Papa en el Ecuador. Quito, Ecuador: COSUDE-INIAP. 
Critchley, W., M. Verburg, and L. van Veldhuizen, eds. 2006. Facilitating Multi-Stakeholder Partnerships: Lessons from PROLINNOVA. Promoting Local Innovation. Silang, Cavite, Philippines: International Institute of Rural Reconstruction; Leusden, the Netherlands: PROmoting Local INNOVAtion in ecologically-oriented agriculture and NRM, and ETC EcoCulture.

Devaux, A., D. Horton, C. Velasco, G. Thiele, G. Lopez, T. Bernet, I. Reinoso, and M. Ordinola. 2009. "Collective Action for Value Chain Innovation in the Andes." Food Policy 34: 31-38.

Dorward, A., J. Kydd, C. Poulton, and D. Bezemer. 2009. "Coordination Risk and Cost Impacts on Economic Development in Poor Rural Areas." Journal of Development Studies 45 (1): 1-20.

Gibbon, P. 2001. “Agro-commodity Chains: An Introduction.” IDS Bulletin 32 (3): 60-68.

Harper, M. 2010. Inclusive Value Chains: A Pathway Out of Poverty. Hackensack, NJ, US: World Scientific Publishing.

Howells, J. 2006. "Intermediation and the Role of Intermediaries in Innovation." Research Policy 35 (5): 715-728.

Klerkx, L., and C. Leeuwis. 2009. Strengthening Agricultural Innovation Capacity: Are Innovation Brokers the Answer? Working Paper Series 2009-019. Maastricht, the Netherlands: United Nations University-Maastricht University-Merit.

Klerkx, L., A. Hall, and C. Leeuwis. 2009. "Establishment and Embedding of Innovation Brokers at Different Innovation System Levels: Insights from the Dutch Agricultural Sector." Technological Forecasting \& Social Change 76: 849-860.

Lambert, D. E. 2008. Supply Chain Management: Processes, Partnerships, Performance. Third edition. Jacksonville, FL, US: The Hartley Press.

Lundy, M., M. Gottret, and J. Ashby. 2005. Learning Alliances: An Approach to Building Multi-stakeholder Innovation Systems. Brief. Rome: CGIAR Initiative on Institutional Learning and Change.

Manrique, K., and R. Egusquiza. 2009. "Muña (sp. Minthostachis mollis) Essential Oil, as a Natural Alternative to Control Potato Sprouting Tested under Different Storage Conditions." pp. 194. In 15th Triennial Symposium of the International Society for Tropical Root Crops, 126-130. www.istrc.org/images/Documents/Symposiums/Fifthteenth/s7_manrique.pdf.

Markelova, H., R. Meinzen-Dick, J. Hellin, and S. Dohrn. 2009. “Collective Action for Smallholder Market Access." Food Policy 34: 1-7.

Meinzen-Dick, R. S., A. Devaux, and I. Antezana. 2009. "Underground Assets: Potato Biodiversity to Improve the Livelihoods of the Poor." International Journal of Agricultural Sustainability 7 (4): 235-248. http://dx.doi.org/10.3763/ijas.2009.0380. 
Ostrom, E. 2005. Understanding Institutional Diversity. Princeton, NJ, US: Princeton University Press.

_. 2010 "Beyond Markets and States: Polycentric Governance of Complex Economic Systems." American Economic Review 100: 1-33.

Pumisacho, M., and I. Reinoso. 2003." ECAs Como Respuesta de la Modernización del Estado: Experiencias en Ecuador." LEISA June: 22-24.

Reardon, T., and J. A. Berdegué. 2002. "The Rapid Rise of Supermarkets in Latin America: Challenges and Opportunities for Development." Development Policy Review 20 (4): 371-388.

Reardon, T., C. Barrett, J. Berdegué, and J. Swinnen. 2009. "Agrifood Industry Transformation and Small Farmers in Developing Countries." World Development 37 (11): 1717-1727.

Reinoso, I., H. Pico, M. Pumisacho, F. Montesdeoca, C. Monteros, X. Cuesta, and G. Thiele. 2007. Cadenas Agroalimentarias: Plataformas de Concertación y Proyectos Compartidos. Quito, Ecuador: Instituto Nacional Autónomo de Investigaciones Agropecuarias.

Röling, N., C. Leeuwis, and R. Pyburn. 2002. "Beyond the Aggregation of Individual Preferences: Moving from Multiple Cognition in Resource Dilemmas." In Wheelbarrows Full of Frogs: Social Learning in Rural Resource Management, edited by C. Leeuwis and R. Pyburn, 25-47. Assen, the Netherlands: Koninklijke Van Gorcum.

Scott, G. 1985. Markets, Myths and Middlemen. Lima, Peru: CIP.

Thiele, G., R. Oros, C. Velasco, and K. Ambrose. 2005. “Por Qué Trabajar Con Plataformas?” In Conceptos, Pautas y Herramientas, edited by G. Thiele and T. Bernet, 66-70. Lima, Peru: CIP.

Thiele, G., A. Devaux, C. Velasco, and D. Horton. 2007. "Horizontal Evaluation. Fostering Knowledge Sharing and Program Improvement within a Network." American Journal of Evaluation 28 (4): 493-508.

Thomann, A., A. Devaux, M. Ordinola, M. Cuentas, P. Urday, M. Sevilla, and J. Andrade-Piedra. 2011. "Native Potato Market Chain and Poverty Reduction: Innovation around Corporate Social Responsibility." In Innovation for Development: The Papa Andina Experience, edited by A. Devaux, M. Ordinola, and D. Horton, 263-275. Lima, Peru: CIP.

Vellema, S., G. Ton, D. Nakimbugwe, D. Mwesige, and D. Moses Opeero. 2009. New Forms of Collective Action in Agri-food Chains: Learning from the Uganda Oilseed Sub-sector Platform (OSSUP). 